\title{
The development of small scale farming: two cases from the Commonwealth Caribbean
}

\author{
D. T. Edwards
}

Department of Agricultural Economics and Farm Management, University of the West Indies, St. Augustine, Trinidad, West Indies

Received 7 October, 1968

\section{Summary}

Two very different cases of small scale farm development in the Commonwealth Caribbean are reviewed. One is Jamaican small farming, which responded little to considerable efforts made for its improvement by the Government agencies. The other is market gardening at Aranjuez, Trinidad where production grew at an extremely rapid rate in the face of intense and antagonistic competition between the gardeners and without significant direct assistance by official agencies. Proximate explanations are drawn for the sharply contrasted performances, and some conclusions are offered.

\section{Introduction}

Two quite different cases have been chosen for consideration. One is well established but apparently highly resistant to change while the other is changing very rapidly. Both cases have been the subject of unusually thorough studies ${ }^{1}$. The first case is that of small scale or peasant farming, as it was practised in Jamaica in the 1950's. The second case is the small scale production of vegetables in a particular part of Trinidad, Aranjuez.

Small scale farming came into existence in Jamaica following the Emancipation of the Slave Population in the early part of the 19th Century. In 1954, farms of from 1 to 25 acres numbered about 150,000 , out of a total number of farms of about 200,000 , and occupied over 700,000 acres of the total area of about 2,000,000 acres of land in farms. The small farms used a considerable part of the resources employed in agriculture, and provided almost one-half of the total agricultural product, and virtually all the locally produced foods, with two or three important exceptions.

The farms actually studied in Jamaica averaged about 10 acres, of which 3.5 acres were cropped. The average value of capital investment was $£ 650^{2}$ of which threequarters was farm rather than domestic capital, virtually all in the form of land, growing crops and livestock. Annual farm expenditure, other than on hired labour, averaged $£ 34$ per farm. The farm households consisted, on average, of six persons: about sixty per cent of the farm people were adults and the remainder were less than 14 years of age. The hours worked by household and other labour averaged between

1 This paper has, of necessity, drawn heavily on the work by Edwards and MacMillan. The research leading to the doctoral thesis by MacMillan was supervised by the author of this paper. (Edwards, 1961 ; MacMillan, 1967 and 1968).

$2 £ 1$ (Jam.) $=\$ 4.80$ (Trinidad \& Tobago).

$£ 1 \quad($ Jam. $)=£ 1 \quad$ (Sterl.).

$\$ 1.00$ (Trinidad \& Tobago) $=\$ 0.50$ (U.S.). 
3,500 and 4,000 hours per farm per annum.

Small farming in Aranjuez differs in many respects from Jamaican small farming. The total area is only 450 acres, and is held in average areas of only 1.5 acres. Cropping is restricted to vegetables, for the nearby Port-of-Spain and adjoining suburban markets. In fact the area is confined within a suburban setting. It is bounded on two sides by the main roads which connect the Capital city with its more distant suburban areas. The gardeners themselves reside in areas which are shared with families engaged in urban employment.

The layout of the gardens has an important bearing on the changing vegetable production systems. The area is flat and open, being unobstructed by buildings and foliage. The small average size of plot, the distribution of a gardener's holding between scattered plots, and the many paths which cross the area, all facilitate the spread of information on the state of an individual farmer's crops and the practices associated with them.

The main purpose in reviewing these contrasting cases is to throw light on both the obstacles to and the process of rapid small farm development. It is also hoped that some lessons of more general relevance can be drawn from a discussion of the two particular cases.

\section{The Jamaican case}

While it is not possible to produce statistics on the growth of output over an appreciable period of time for the particular small scale farms studied, data are available for the small farm sector to which the small farms studied belonged (Edwards, 1968). Thus between 1943 and 1961 the output of the farms of less than 25 acres increased by only about $15 \%$, measured in real terms. (The output of all other farms increased by $76 \%$ over the same period.) This very slow growth in output occurred in spite of considerable efforts on the part of Government agencies, supported by substantial resources, to bring about small farm development.

What accounted for the sluggish growth? Were the farmers uninterested in higher incomes? Were they unprepared to change their farming systems? In short, what were the possibilities of bringing about farm development in the Jamaican environment? The review of the Jamaican case will address itself to these questions.

\section{The objective of increased income}

There is ample evidence to show that the small farm families desired higher incomes: for reinvestment in farming, to provide more adequate food and clothes, to extend and improve housing, to educate the children, and to establish adequate liquid reserves. But it is equally clear that the farmer's objectives were more complicated than simply the 'maximisation of income'.

The farmer's objective was to produce income both in the near and the distant future ${ }^{3}$. His immediate aim was to obtain sufficient income to sustain his family and

s This concern with both the immediate and distant future sometimes resulted in the paradoxical situation where a farmer who refused to plant a crop of bananas alone, because he could not wait a year for it to bear, was prepared to plant trees which would not start bearing for several years. The explanation is that the establishment of trees promised highly valued security for the farmer's old age; the trees would produce useful crops with very little labour, while the banana crop offered neither income in the immediate future nor security for his old age. Similarly, land was bought even when its purchase reduced the possibilities of investment in cultivation, because the possession of land ensured that the farmer would be provided for in his old age. 
to maintain or to expand his farming. At the same time he wished to ensure security in his old age and to acquire ownership of land, which might be left to his children and possibly his wife. The objective of obtaining income was influenced by two other aims: to be accepted by the community, and to have maximum independence. Signs of a substantial increase in income were likely to bring increased prestige but might also earn resentment: while a substantial fall in income would almost certainly bring lower status and loss of prestige in the community. Greater dependence on other persons would follow an appreciable fall in income; a greater degree of independence would crown a profitable venture.

The farmers had goals for their farming practice which governed the means by which their income and security objectives would be realised through farming. They tried to promote what they regarded as good small farming, which involved having most of the farm land under 'good' cultivation. The crops should be well tended, according to the practice of the district, the ground between crops should be clean weeded. A crop like banana should be well pruned (that is, dead leaves should be trimmed off and surplus young banana plants removed) and operations should be 'timely'; but it was not regarded as desirable that improved techniques, such as fertilizing, should be employed. Still the crops should 'look good', that is, appear healthy and likely to give good yields.

The farmers were concerned about maintaining the fertility of their land - so that they could obtain what they regarded as good crop yields. They practised soil conservation measures, which prevented yields from falling excessively over the period for which the land was used continuously. The land was then abandoned for a few years while it 'rested' and fertility was rebuilt.

There was a widespread feeling that the farms should produce certain crops, the particular ones depending on the area. Thus in some areas banana was expected to dominate the other crops; banana should occupy all the land on which it would grow while the other crops were to be fitted in as best they could. It was considered necessary in all the areas that more than a few crops should be grown, some to provide food for the household and some to provide cash.

\section{Scope for improvement of the farming systems}

Jamaican small farming has been strongly criticised on 'technical' grounds. In the words of a Mission from the International Bank for Reconstitution and Development (I.B.R.D., 1952, p. 13), the farmers were "..... in general the most inefficient, partly because their agricultural techniques were the most backward". Thus even though labour was applied quite intensively to land (at about 600 hours per acre of crop land per year) the yields of individual crops were very low and erosion occurred at an appreciable rate. The effect was that even though the farmers worked hard and the prices they received for their products were generally very favourable by international standards, the level of living they enjoyed was quite low.

In the circumstances a large number of improved practices were recommended for use on Jamaican small farms. Their application would undoubtedly have led to higher yields and (if increased aggregate production would not have reduced product prices excessively), also to higher net incomes. But the farmers were not prepared to introduce most of the practices. How can this 'perversity' be explained?

Reactions to the use of improved practices: the pattern of entrepreneurship Most improved practices were rejected by Jamaican small farmers, but in some in- 
stances improved practices have been introduced into the farming systems. The recognition of these exceptions assists in appreciating the whole pattern of entrepreneurship in its reaction to potential innovations.

Two sets of exceptional circumstances may be identified as conducive to the adoption of new practices. These are situations of crisis, and situations where the ecological environment is radically changed. Thus there have been occasions when diseases have so severely affected crops that the farmers have been prepared to introduce the simple and cheap, yet highly effective treatments. The introduction of a system of irrigation throughout an area by changing the ecological conditions made possible the highly profitable replacement of familiar 'catch' crops by 'new crops' (such as rice), which led to the widespread introduction of modern practices, as the traditional system of dry land cultivation had to be set aside.

A clearer illustration of open-mindedness to innovations is demonstrated by the employment under normal conditions of a new practice on a small scale. In some instances these practices have been recommended by other persons, in other instances the practices have been formulated by the individual farmer.

The most important examples of innovations for the present argument are commonly overlooked. These are of crops and practices which have been widely introduced by the initiative of individual farmers ${ }^{4}$. Indeed it seems probable that a significant, if modest, part of useful farm practice which spread amongst small farmers, was also introduced by small farmers.

Under their conditions of limited resources the farmers knew more profitable forms of investment in familiar practices than they had resources to invest. In these circumstances it was understandable that they rejected unfamiliar practices almost entirely. No specific case of discontinuing probable returns (that is, reducing estimated returns by an uncertainty allowance) was encountered amongst the farmers studied, but their knowledge of the improved practices was so slight - in some instances they did not even know how the practices should be employed and did not have the requisite skills for their introduction — that in effect they employed this safe-guard, making generous allowances for their great uncertainty.

The supply of resources was so limited that even all the familiar lines of investment could not be used to the extent the farmers thought desirable. They had to choose between various possible uses, taking into account the likely profitability and security of the investment and their own and their families' preference on non-economic grounds for various practices.

Some of the principal reasons given for rejecting some familiar practices while adopting others were:

(i) lack of sufficient resources of the kinds needed to invest in all the familiar practices (the resources included skills and organizational ability as well as adequate labour and capital, and suitable land);

(ii) those practices adopted were believed to offer more profitable uses for the available resources;

(iii) although the average level of profitability might have been high the risk of loss at any particular time was unacceptably high;

(iv) the adoption of certain practices would have involved discontinuing others, but

- A striking illustration is provided by peanuts which have become an important element in the farming system of South St. Elizabeth in Jamaica. 
the farmer was satisfied with the prevailing practices and saw no reason why they should be replaced;

(v) refusal by the farmer to meet the discouragement of members of his family and other persons if they did not approve a practice he favoured; and

(vi) lack of incentive due to the farmer's old age or illness.

The farmers' reaction to the use of improved practices can only be understood when considered as part of their entrepreneurial behaviour in the context of the conditions of risk and uncertainty prevailing in their environment. They responded to these conditions not only by employing familiar practices and rejecting unfamiliar practices except under special circumstances, but also by: - refusing to borrow against the security of land; maintaining reserves; producing many products; and making some payments in kind rather than cash.

Their refusal to finance investment in unfamiliar practices (and their limited investment in improved practices) allowed the farmers to avoid borrowing substantially, and to maintain reserves of cash, land and unused credit from official and unofficial sources. Relatives, friends, and persons to whom the farmer had lent funds in the past, represented the unofficial sources of unused credit. The farmer's assets in the form of livestock also constituted a reserve which was reasonably safe as well as liquid.

Beside providing this reserve the livestock enterprises served to diversify the farming systems. This diversification (and liquidity) was bought at the cost of income, for the productivities of resources employed in the livestock enterprises were appreciably lower than those of resources in crop enterprises in the same farms. The large number of crops grown not only diversified the systems ${ }^{5}$, but also served other purposes. The period during which crops are reaped is generally longer for many than for a few crops, thus reducing the need for seasonal credit. The inclusion of tree crops provides for the farmer's old age: when his declining strength prevents him from working hard he is able to reap from the tree crops which, unlike the short term and semi-permanent crops, require little attention once they are established.

The farmers conserved their funds in favour of expending other resources, particularly their family labour: labour tenancies, share tenancies (land and livestock), and payment for labour by the return of labour with food, were all arrangements adopted to reduce the need for making cash payments.

The funds of both tenants and owners were safe-guarded by some of these arrangements: thus the owner of land which was share-cropped was spared expenditure on hiring labour for cultivation, and the tenant avoided payment of a cash rental. In short the small farmers so managed their financial opportunities and pattern of farm expenditure that they reduced both the need to draw on their own cash reserves and to borrow from sources which did not find them attractive clients. They adjusted their whole economic behaviour to conserve the expenditure of funds.

\section{The possibility of farm development}

An appraisal of Jamaican small farming led to the view that it generally represented a rational if not optimal response in the circumstances in which it was conducted.

5 Diversification of crops in the systems commonly extended to mixed cropping. There is some reason to believe that under conditions of capital rationing and a generally poor level of techniques, this practice results in a more productive use of resources than growing the crops separately. 
Given the family needs and their limited resources, a strategy which concentrated on ensuring modest but safe returns ('staying in the game') in the face of great uncertainty constituted a sound policy.

However, the farm people did not regard the returns as adequate. There was a strong 'felt need' for a level of income which could only have been obtained from a more lucrative farming, which would have to be very different from the prevailing kind. It would seem that there were present some of the elements necessary for the development of small farming in Jamaica: the demand for higher income, a qualified willingness to introduce new practices, and a large number of improved practices available for adoption. Could not these be mobilised to bring about a transformation of farming from a low-return, multi-enterprise system based on customary knowledge, to a more profitable system made up of only a few enterprises, which employed modern scientific practices? The magnitude of the change involved becomes apparent from the terms of the question. Possible approaches to the development of small farmers will be discussed after looking at the second case.

\section{The Aranjuez case}

Vegetable production in Aranjuez became well established only in the late 1940's. Originally, Aranjuez had been a small sugar estate, but following the depression in the 1890's the estate was given out in small-holding tenancies to labourers who had completed their contractual obligations as indentured labourers. They grew sugar cane and supplied it under contract to sugar factories.

Sugar cane remained the principal crop until the 1930's when many of the cane farmers withdrew from production, following the fall in cane prices which accompanied the world depression. Some wet season rice was grown for family use.

In 1937 the infra-structure of Aranjuez was greatly improved. Access roads were put down in the main agricultural areas, a dam was constructed and irrigation and drainage channels dug. The sustained production of vegetables did not commence until the late 1940's. Since that period production has increased very rapidly. Between 1950 and 1966 the production of vegetables from 450 acres at Aranjuez grew from less than one million pounds (lbs.) to over six million pounds, at an average compound rate of growth of $14 \%$.

The two components of this high rate of increase were an increase in land-use intensity of 3.3 times $^{6}$ and a doubling of yields per crop acre. The increased production came about as a result of a wide range of technical improvements. These are reflected in the resource combinations for Aranjuez, which may be compared with the resource combinations in Jamaican small farms:

\begin{tabular}{|c|c|c|}
\hline & $\begin{array}{c}\text { Aranjuez } \\
\text { (per crop acre) }\end{array}$ & $\begin{array}{c}\text { Jamaica } \\
\text { (per crop acre) }\end{array}$ \\
\hline Labour & $1,650 \mathrm{hrs}$. & $600 \mathrm{hrs}$ \\
\hline Expenditure on materials & $£ 69$ & $£ 3$ \\
\hline Expenditure on tractor costs & $£ 14$ & \\
\hline
\end{tabular}

Thus not only is 2-3 times as much labour employed at Aranjuez as in Jamaican small farms, but the expenditure on materials and tractor costs is also at a very much higher rate.

3 Land-use intensity is measured by the acreage of crops grown per year, per 1 acre of cultivated land. 
The innovations: their introduction and spread

The most significant innovations have been the use of: tractor mounted rotovators for land preparation, fertilizers, new crop varieties, and chemical weed killers.

Sources of information. The gardeners themselves have given the following order of priority in ranking their main sources of information:

(i) MacDonald's Almanac 7,

(ii) radio,

(iii) other gardeners,

(iv) newspapers,

(v) commercial salesmen,

(vi) Agricultural societies,

(vii) University staff.

(It will be noted that agricultural extension officers are not even mentioned.)

Although there were several sources of agricultural knowledge used by the gardeners, two of these - salesmen of agricultural requirements and University staff - were responsible for first introducing to the gardeners information on the most important innovations which have been employed in Aranjuez.

Many of the important innovations have been sought and introduced by the gardeners with outstanding initiative. Few innovations have been sought and introduced by group or community action.

The spread of innovations. Once a new technique has been adopted by any gardener in Aranjuez its use spreads widely and rapidly. Within a few years innovations have been adopted by most gardeners.

This record would be notable if there was general co-operation between the gardeners, but in the face of the intense competition which exists, the rate at which innovations spread is even more remarkable. How does this occur? The process depends on the competitiveness of the community. The gardeners live in residential areas with persons, working outside agriculture, who generally earn substantially higher incomes. Since prestige tends to be associated with material possessions, the gardeners are constantly under pressure to earn higher incomes.

Improved technology and hard work are the means at hand to acquire higher prestige. There is great incentive to employ new and profitable techniques, partly for the hope of increased income, but also for the admiration of other gardeners which is displayed towards a progressive gardener. This climate has produced not only 'leaders in innovation', who achieve high crop yields, have well kept gardens, and are innovators, but also a general spirit of professionalism amongst the gardeners which takes pride in the use of new methods. The competitiveness is sufficiently acute to lead some gardeners to hide the cause of success from their fellows and even to try to mislead them ${ }^{8}$. (One device used to mislead fellow gardeners is to leave near the gardens - apparently by negligence - empty crop chemical tins which have had the correct labels replaced by other labels. Gardeners who find the tins will initially

7 MacDonald's Almanac is an annual publication produced in the United States of America which advises on a wide range of problems, based on the phases of the moon. It is widely used throughout the Commonwealth Caribbean.

8 A recent account of scientific research leading to the discovery of DNA is useful as a reminder that extreme competitiveness is not the monopoly of poor men fighting for a living (Watson, 1968). 
draw the wrong conclusion about chemicals used.) But the closeness and openness of the gardens militates against such measures being more than temporarily successful: information cannot be hidden from persistent observation and investigation.

\section{The possibilities for sustained development}

In view of the remarkable past growth of production in Aranjuez is it feasible for production and income to be increased substantially in the future? It has been estimated that a family cultivating an average sized holding of $11 / 2$ acres would have earned in 1966 about $\$ 1,900$ (T.T.) (c. $£ 396$ ) or $\$ 2,300$ (T.T.) (c. $£ 479$ ), if all the labour was provided by the gardener's family.

A careful review of the possibilities of improvement available to the individual gardener suggested that yields of important crops could be increased by at least $20 \%$. Variable costs per acre of crop could be reduced. Most of the reduction would derive from mechanising labour-intensive methods, but there is also scope for saving by the restriction of excessive use of expensive chemicals for crop protection ${ }^{9}$. Gross margins - the difference between gross revenue and variable costs - of two main crops could be increased by about $63 \%$ for tomatoes and $132 \%$ for cabbage, per acre of crop.

There are other improvements which would require co-ordinated or co-operative action by the gardeners for their implementation. These improvements relate to the infrastructure and the process of marketing the produce of Aranjuez.

The conditions of the roads and of the water control system have been deteriorating: the resulting loss of income to the gardeners is real and appreciable. The worsening of the internal roads causes, as a direct result, an increase in the price of transportation, which in turn restricts the area under cultivation and reduces the choice of crop. Inadequate water control has tended both to intensify flooding during the wet season and to reduce the water available for crops during the dry season. In these ways the operational costs and the product of land in Aranjuez has been adversely affected. When the water supply is too low, labour has to be spent not only in lifting the water to the crops but also in carrying the water to the fields by blocking and unblocking the appropriate canals, and by patrolling the supply to ensure that other gardeners do not divert water at the expense of the individuals. A new central system of irrigation is required.

If investment in the infra-structure was directed to improving the roads and the system of water control, there could be significant savings in the cost of several production operations and the uncertainties in production would be reduced: the area under cultivation would almost certainly be increased also.

The practice of the individual gardener transporting his produce to the main market and selling it personally to a retailer clearly also represents a high and unnecessary cost to the community of gardeners, which does not require elaboration. There is, therefore, considerable scope for returns to the gardeners to be improved; but cooperative action is required by the gardeners.

The gardeners have been outstanding for their individualistic and even antagonistic competitive behaviour. The only significant cases of large scale co-operation have been provided by concerted protest and opposition. Thus the gardeners have sent innumerable delegations to Government bodies protesting about conditions which adversely

9 It is interesting that the gardeners have no real understanding of the science of, or close commercial sense of the limits to the use of the chemical substances which are employed so extensively. 
affect their welfare. But more positive manifestations of united action have been conspicuously absent.

A willingness to co-operate has to extend not only to other gardeners, but also to external agencies, such as the Central Marketing Agency, if common services are to be provided economically for the gardeners. Experience in this respect has been discouraging.

The improvement of the infra-structure would also require a common willingness and even demand amongst the gardeners for the payment of much higher rental charges for their gardens. The present level of rents - between $\$ 6.00$ and $\$ 10.00$ (about $£ 1-£ 2$ ) per acre per year — is not sufficient to support even routine maintenance. Despite the profitability of their vegetable production the gardeners are not prepared to pay to the Estate Company, which owns the land, higher rentals than were imposed in 1937, when the present infra-structure was established. In contrast gardeners pay each other between $\$ 70.00$ ( $£ 15$ ) and $\$ 200.00$ (c. $£ 42$ ) for the use of an acre of land for only a few months to grow a single crop, while tenancy rights have been sold for between $\$ 900.00$ (c. $£ 190$ ) and $\$ 2,000$ (c. $£ 417$ ) per acre in a recent year.

The gardeners are paying an extremely low rental to the Estate Company for land with a deteriorating infra-structure, which if allowed to decline further will not only reduce the returns from gardening, but will lead to the collapse of the whole system and the transference of land to residential use. Indeed unless the gardeners are successful in ensuring that the infra-structure is improved, at the cost of paying higher rents (estimated to be of the order of $\$ 80.00$ (c. $£ 17$ ) per acre), the collapse of market gardening at Aranjuez can confidently be predicted.

\section{Discussion}

It is possible to characterise the contrasting approaches of the Jamaican and Aranjuez small farmers by saying that while the Jamaican small farmer was unprepared as an individual to risk widespread innovation in farm practices, the Aranjuez gardener adopts new technology to ensure that he will not be left behind in farming practice and in material welfare. Both groups of farmers are pervaded by a competitiveness which attempts to ensure that their fellows do not get ahead of them. But whereas in the Jamaican case the effect was generally for individual innovation to be constrained, in the Aranjuez case the individual responds by striving for material advancement through innovation.

This difference in response is not simply explained by the relative efficacy of the practices recommended to Jamaican small farmers as against those employed by the Aranjuez gardeners. While it is true that the technology employed in Aranjuez has been generally remunerative, profitable practices were also available to the Jamaican small farmer. Possibly the essential difference is that whereas the aggressive entrepreneurs of Aranjuez have learnt from experience that innovation is commonly profitable, the experience of the Jamaican small farmers has not proved the attractiveness of new technology, thus reinforcing the discouragement to innovation from their communities.

How can the extremely common situation described in the Jamaican case be tackled? This is, of course, too big a question to be discussed adequately at the end of a short paper, but the cases considered suggest certain strategies which will be in- 
dicated, after reference to two other common approaches. The 'rational' approach to farm development - persuasion that a change would be to the objective benefit of a farmer - is an important ingredient in many programmes of farm improvement. Another approach, improvement by imposition, has been much more widespread than is commonly recognised. If 'extension by the sabre' has been confined to totalitarian regimes, other forms of imposition, through law, regulation and even administrative decision, have been practised under varied political systems, albeit for reasons other than the primary benefit to the individual farmer. (The requirements of public health, for instance, has a marked effect on the practice of livestock production in the developed countries.)

The case studies emphasise the influence of community cultural practice on the individual. The experience at Aranjuez demonstrates strong progressive influence. The effect displayed in Jamaican small farming has most frequently been inhibiting, but instances have been noted of community influence leading to widespread adoption of an innovation. Thus, in addition to the rational approach and to imposition, the pressure to conformity in community farming holds promise as a means of spreading improved practices. Widespread introduction of farm practices, so that a popular pattern is created, may sometimes be more a question of using techniques of persuasion than appealing 'rationally' to objective benefits. There is certainly no reason to believe that innovations in farming are made only as a result of purely economic assessments.

A pessimistic view of the problems of transforming a highly complicated but relatively safe farming system, into one which has fewer but very demanding enterprises might lead to the view that a radically different approach is necessary. The transformation of the farming system may seem to be beyond the acceptance and capacity of the small farmer. Even the demands on the research and extension staff - to provide profitable small scale farming systems for the various ecological areas - and on the provision of improved infra-structure and agricultural services, which have to be met to provide the conditions for general small farm development, are formidable. The problems may be reduced to a more manageable compass by producing new farmers, through training carefully selected farmers or trainees, for introduction to adequate ready-made farms.

A quite different kind of approach or strategy to farm development derives from a more macro-view of agricultural development, which recognises the influence of the economic environment on the farm business. The implication for farm development is that manipulation of the environment through the battery of measures available to a government can exert a profound if indirect effect on farm practice. The experience of Aranjuez certainly confirms the possibility of rapid growth being stimulated by a favourable environment. It has to be recognised that the indirect measures available to a government cannot be applied with the precision available to the more direct means of approach, through work with individual farmers. But reference to the formidable problems of organising an effective system of agricultural extension capable of reaching large numbers of small farmers, and the disappointing experience in so many countries of the 'classical' extension approach, suggest the need for other approaches to be seriously explored. It may be that attempts to produce a favourable environment will commonly need to be seen as complementary to the extension or field agent approach. 


\section{Some conclusions}

Four main conclusions emerge from a study of the two cases.

Outside agencies may not be effective in bringing about the development of small farms despite considerable effort and the investment of a substantial volume of resources, as in the Jamaican case.

But small scale producers may respond in a spectacular way to a favourable environment, as have the market gardeners of Aranjuez, even without much direct official assistance.

Rapid growth in production may be checked when the avenues open to individual effort are used up, unless co-operative action allows common needs for further growth to be met.

Finally, several strategies are seen as possible approaches to farm development. Amongst direct strategies are included: the 'rational', the imposed, community persuasion, and the creation of new farmers and new farms. There is also the indirect strategy, whereby an attempt is made to arrange an economic environment favourable to farm development.

\section{Acknowledgements}

The author is indebted to A. A. MacMillan for providing access to a manuscript in the process of preparation and for sharing his ideas on Aranjuez at a formative stage in the preparation of this paper and to Miss O. M. Strachan who made useful comments on an advanced draft of this paper.

\section{References}

Edwards, D. T., 1961. An economic study of small farming in Jamaica. Inst. of Soc. and Econ. Res. UCWI, Jamaica.

Edwards, D. T. Agricultural development in Jamaica, 1943-1961. (Paper read at the Third West Indian Agricultural Economics Conference, April 1968).

International Bank for Reconstruction and Development, 1952. The economic development of Jamaica. The John Hopkins Press, Baltimore.

MacMillan, A. A., 1967. Aranjuez, Agricultural development in a suburban setting. Proceedings of the Second West Indian Agricultural Economic Conference, August 1967 (UWI, St. Augustine): 216-227.

MacMillan, A. A., 1968. The development of market gardening in Aranjuez, Trinidad. Ph.D. thesis, UWI, St. Augustine.

MacMillan, A. A. and Edwards, D. T. Aranjuez: Change in a market gardening community in Trinidad - a case study, 2d, (prepared for the International Seminar on Change in Agriculture, held at Reading University in September 1968).

Pickering, R. H., 1968. A critical examination of wholesale marketing, as conducted by the market gardeners of Aranjuez, Trinidad. DTA Project Report, UWI, St. Augustine.

Reader, R. A., 1968. The scope for mechanisation of vegetable production in Aranjuez, Trinidad. DTA Project Report, UWI, St. Augustine.

Watson, J. D., 1968. The Double Helix. Weidenfeld and Nicolson, London. 